\title{
Comparative Analysis of two Methylobacterium spp. for Mitigating Moisture Stress Induced by PEG in Early Growth Stages of Tomato
}

\author{
P. Anitha ${ }^{1}$, K. Kumutha ${ }^{1}$, C. Raja Manickam ${ }^{2}$, A. Kamaraj ${ }^{3}$ and M. Senthilkumar 3* $^{*}$ \\ ${ }^{1}$ Department of Agricultural Microbiology, ${ }^{2}$ Department of Horticulture, Agricultural College \\ and Research Institute, Tamil Nadu Agricultural University, Madurai-625 104, India \\ ${ }^{3}$ Department of Crop Management and Research Institute, Tamil Nadu Agricultural \\ University, Eachangkottai-614902, India \\ *Corresponding author
}

A B S T R A C T

\section{Keywords}

Environmental stresses, $\mathrm{CO} 2$ reduction, day neutral plant, tomato

Article Info

\section{Accepted:}

15 March 2021 Available Online: 10 April 2021
Tomato (Solanum lycopersicum) is widely cultivated vegetable crop and processed throughout the world which is highly susceptible to moisture stress. In this study Methylobacterium spp. viz., $M$. aminovorans and $M$. thiocyanatum were used to increase the moisture stress tolerance. Artificial moisture stress was induced to tomato seeds using Polyethylene Glycol (PEG) with concentration ranged from 0 to -3 bars. The results showed that highest growth parameters were exhibited in tomato seedlings treated with M.thiocyanatum, where it exhibited maximum germination percentage at 0 bar $(42.7 \%)$, vigor index at 0 bar (170.8), shoot length at -3 bar $(2.7 \mathrm{~cm})$,root and seedling length at -2 bar $(4.1 \mathrm{~cm}, 5.1 \mathrm{~cm})$ followed by M.aminovorans, which showed germination percentage of $40 \%$ at $(-1.5$ bar), vigor index of 131.2 at (1 bar), root, shoot and seedling length of $2.9 \mathrm{~cm}, 1.9 \mathrm{~cm}, 4.8 \mathrm{~cm}$ at $(-3$ bar $)$ respectively. Compared to treated seeds, the un-inoculated control showed lowest germination percentage at 0 bar (17.2\%), vigor index (48.3), root, shoot and seedling length $(1.7 \mathrm{~cm}, 1.1 \mathrm{~cm}, 2.2 \mathrm{~cm})$. Root hair deformation was observed in both treated seedlings which are grown under aseptic condition. In which, M. aminovorans performed well when compared to M. thiocyanatum. The activity of antioxidant enzymes catalase (CAT), peroxidase (PER), proline, glycine betaine (GB) and superoxide dismutase (SOD) were enhanced by $M$. aminovorans at -1.5 bars $\& M$. thiocyanatum at -2 bars which have the ability to protect the plant under moisture stress conditions. Thus, Methylobacterium has the ability to mitigate drought stress and increase the drought tolerance of tomato crop. 


\section{Introduction}

Tomato (Solanum lycopersicum) is the most cultivated vegetable crop in the world. The global production of tomato was around 164 million tonnes, which covers an area of 4.8 million hectares with a seventh place rank in productivity (FAOSTAT, 2013; Luna et al., 2016). Presently global productivity of tomato was facing the difficulties of biotic and abiotic stress. While tomato is a day neutral plant and which is highly susceptible to high temperature and drought. Drought is the most important environmental stresses in agriculture which directly reduces the crop growth and yield by limiting the global productivity.

Polyethylene Glycol (PEG - 6000) induces water stress artificially in plants and existence in the form of viscous liquid to solid wax (Larher et al., 1993). It reduces the cell water potential by inducing osmotic stress (Govindaraj et al., 2010). During the process of photosynthesis the induction of osmotic stress in plants causes changes at the cellular level which affects pigments present inside the chlorophyll (chlorophyll-a \& b) which decreases the rate of photosynthesis, photosystems, and the transport mechanism of electron and pathways of $\mathrm{CO}_{2}$ reduction. Dodd and Donovan, (1999) investigated that drought stress also induced the inhibition of germination (Sidari et al., 2008).

Shukla et al., (2012) reported that diverse tolerance mechanisms occur due to changes in physiological and biochemical process to withstand the drought stress condition. Recent studies had reported that plant-associated bacteria can help more effectively to withstand abiotic stresses (Chauhan et al., 2015). Vadharajula et al., (2011) studied the role of rhizosphere bacteria in stress tolerance but few studies focused on phyllosphere bacteria which involves in improvement of plant environmental condition by suppressing the activity of biotic and abiotic stress. Mostly study on phyllosphere bacteria had focused on individual bacteria isolates using culturedependent methods in terms of their role in pathogen suppression in plant defense (Delmotte et al., 2009) and in plant growth promotion (PGP) (Papen et al., 2002) or through the production of 1aminocyclopropane-1carboxylate (ACC) deaminase. Phyllosphere colonization by Methylobacterium has been reported to produce phytohormones such as cytokinin and auxins (Madhaiyan et al., 2005) and stress response enzyme ACC deaminase (Chinnadurai et al., 2009). Methylobacterium influences seed germination and plant growth by cytokinin and auxin synthesis (Omer et al., 2004; Tani et al., 2012; Eevers et al., 2015), nitrogen fixation (Sy et al., 2001; Madhaiyan et al., 2014) and plant protection (Ardanov et al., 2012; Madhaiyan et al., 2006, Yim et al., 2014). Exogenous use of PPFM has some advantages in alleviating the adverse effects of drought stress and also improves the germination, production, development, quality and yield of crops (Hayat et al., 2010).

The aim of the present study was to investigate the comparative effect of two species of Methylobacterium and generated osmotic stress by different concentration of PEG on seedling characters, root hair deformation assay and biochemical parameters of tomato.

\section{Materials and Methods}

Bacterial strains, culture conditions and plant material

The Methylobacterium strains: $M$. aminovorans (MtTm13) (KC568445), $M$. thiocyanatum $\left(\mathrm{DSM} 11490^{\mathrm{T}}\right)$ were obtained from Department of Agricultural Microbiology, Agricultural College and 
Research Institute, Madurai, Tamil Nadu. Methylobacterium strain were cultured in Ammonium Mineral Salt (AMS) broth with $0.5 \%$ methanol and these bacterial cells were incubated for 10 days to get a maximum cell population of $10^{9} \mathrm{cfu} \mathrm{ml}^{-1}$. The tomato seeds variety PKM1 were obtained from Department of Vegetable Crops, Horticultural College and Research Institute, Periyakulam, Tamil Nadu.

\section{Mechanism of inducing Drought stress}

The experiments were performed in petridish under In vitro condition. The tomato seeds are surface sterilized with $0.02 \% \mathrm{HgCl}_{2}$ for 5 minutes followed by $70 \%$ ethanol for $1 \mathrm{~min}$ followed by two subsequent rinses in sterile distilled water. Twenty five seeds per treatment were soaked in respective Methylobacterium spp. for 4 hours in liquid cultures $\left(10^{9}\right.$ colony-forming units [CFU] $/ \mathrm{ml})$ ). The treatments are $\left(\mathrm{T}_{1}\right)$ un-inoculated seeds (control) treated with sterile distilled water; $\left(\mathrm{T}_{2}\right)$ seeds inoculated with M.aminovorans; $\left(\mathrm{T}_{3}\right)$ seeds inoculated with M.thiocyanatum. The seeds were drained in laminar air flow cabinet for 10 minutes. Then the treated seeds were placed in a petridish containing filter paper, untreated seeds were taken as control and kept in an incubator.

After 12 hours respective concentration of PEG solution (0 to -3bars) was applied to each treatment. Number of seeds germinated was manually counted on each day up to 15 days and the seed germination characters were considered based on the emergence of radicle and plumule. The experiment was performed in five replicates for each treatment and statistical analyses were carried out and compared the growth of both treated and untreated seeds added with PEG. On $15^{\text {th }}$ day, speed of seed germination (Maguire 1962), germination percentage, vigor index (Abdul Baki and Anderson, 1973), root and shoot length was observed

\section{Root hair deformation assay}

The surface sterilized tomato seeds as mentioned in above process were treated with Methylobacterium strains and placed in moistened filter paper in a petridish and was incubated at $25^{\circ} \mathrm{C}$. After 12 hours of incubation respective PEG solution (0 to 3bars) were added to each treatment. After 5-7 days the tomato seedlings showed abundant root hair growth in lateral root. All the root hairs were observed under microscope by mounting one root per presterilized slide where the entire root was observed to be not deformed. Thus, Methylobacterium strains were added to the seedlings which are kept for a period of incubation, and then the roots of treated seedlings were taken and stained by aniline blue/ lactophenol stain (White et al., 2014) in which root hairs deformation were observed. The experiment was performed in five replicates for each treatment. The treated and untreated seedling root hairs were observed using Bright field microscope (M/s. Olympus, Japan) at 40x magnification. Number of root hairs were counted, morphological feature of primary infected root and root hair length, root hair breadth was observed.

\section{Enzyme extraction and assays}

Fresh tissue (100mg) was homogenized in an ice cold mortar using $50 \mathrm{mM}$ potassium phosphate buffer $\mathrm{pH}$ 7.0. The samples were centrifuged at $11,000 \mathrm{rpm}$ for $25 \mathrm{~min}$ at $4{ }^{\circ} \mathrm{C}$ and the supernatants were used to determine the soluble protein content for SOD, CAT, POX, Glycine betaine and Proline activities. SOD, CAT, POX, Glycine betaine and Proline enzyme activities were determined according to methods described by Dhindsa et al., (1981), Chaparro-Giraldo et al., (2000), Hammerschmidt et al., (1982), Greive and Grattan (1983), and Bates et al., (1973), respectively. 


\section{Statistical Analysis}

The experiments were conducted in completely randomized block design. The results presented are the means of three replicates. The data obtained were analyzed by a one factorial analysis of variance, with substrate as experimental factor using AGRES software as per described by Panse and Sukhatme (1978).Sample variability was estimated by standard deviation of the mean. Analysis of variance was conducted on the data at $\mathrm{CD}(\mathrm{P}=0.05)$.

\section{Results and Discussion}

\section{Effect of PEG -6000 (0 to -3bars) induced osmotic stress on growth parameters}

\section{Speed of germination}

Methylobacterium spp. influenced the speed of seed germination and results were presented in table1. The result showed that un-inoculated control at 0 bar showed earlier speed of germination (1.91) was due to their ability to absorb water in normal condition. Induced drought stress in the seeds by adding PEG reduced the speed of germination. The induced moisture stress by PEG decreased the speed of germination at -1 bar (1.21) followed by 0.86 at ( 0.5 bar), 0.60 at ( -1.5 bar). In the M. aminovorans treated seeds added with PEG showed faster germination of seedlings at -1.5 bar (3.2) followed by -1 bar (3.0), whereas the $M$. aminovorans treated seed with PEG has the 2.3 at 0 bars. In the M. thiocyanatum treated seeds, maximum speed of seed germination was observed at treatment without PEG (0 bar) with other treatments showed decline in germination speed. When comparing other treatments, speed of germination declined as the concentration of PEG increased irrespective of the treatments. In the uninoculated treated seeds with PEG alone the germination was arrested beyond -1.5 bars hence results are depicted from 0 to -1.5 bars presented in table 1. Similar results were found in Febri Doni et al., (2014) rice seeds treated with Trichoderma sp., revealed speed of seed germination were significantly greater than un-inoculated control. Raja et al., (2018) reported that the seed treatment with microbial cultures increased the speed of germination in paddy. The effect of PGPR inoculation was significantly enhancing the speed of germination on Crataegus pseudoheterophylla (Fatemeh et al., 2014). Among the two Methylobacterium species the M. aminovorans treated seeds added with PEG showed faster germination of seedlings at -1.5 bar (3.2). The two species used in this study had confirmed the induced moisture stress tolerance to the treated seeds with varying result.

\section{Germination rate $(\%)$}

Number of germinated seeds of the tomato variety PKM 1 as affected by PEG treatment and the results showed that un-inoculated control had germination rate after 15 days at 0 bar was $17.2 \%$ while the least germinated rate were exhibited at -1 bar $(10.5 \%),-0.5$ bar (7.9\%) and -1.5 bar (4\%). In the $M$. aminovorans treatment had higher germinated rate at -1.5 bar $(40 \%)$ followed by -1 bar $(32 \%)$, while the least germinated rate were exhibited at -3 bar $(18.5 \%)$. Treated seeds of M. thiocyanatum showed earlier germinated percentage at 0 bar without PEG (42.7\%) with other treatments showed decline in germination percentage given in table 1 . Similar results of improved seed germination and also plant growth promotion on tomato under drought condition was reported by Chandrasekaran et al., (2017). Madhaiyan et al., (2006) demonstrated the PGP Methylobacterium containing ACC deaminase in the roots of canola (Brassica campestris) and there by reduced the concentration of ACC and ethylene level due to the activity of bacterial ACCd (ACC deaminase). 
Methylobacterium inoculation increased the IAA concentrations of the plants resulting in increased ACS (ACC synthase) activity.

Saikia et al., (2018) reported that the ACC deaminase-containing methylotrophic bacteria could reduce a significant portion of the plant damage by breaking down the ethylene precursor into ammonia and $\alpha$-ketobutyrate. ACC deaminase produced by bacteria was well proven to mitigate stress in various plants.

Jorge et al., (2019) suggested that the cytokinin plays an important role in host plant metabolism, including stimulation of growth, increased level of photosynthesis and chlorophyll, as well as nutrient allocation and effective water management under drought condition. Kumar et al., (2016) reported that inoculation of Bacillus amyloliqufaciens and Pseudomonas putida enhanced the germination percentage in chickpea under stressed condition due to bacteria had a higher potential to mitigate the stress. Ryu et al., (2006) demonstrated that germination percentage of the Methylobacterium sp., treated tomato and red pepper seeds were comparatively greater when compared with un-inoculated control.

In addition, Meena et al., (2011) reported that enhanced seed germination of wheat (Triticum aestivum) with highest values of $98.3 \%$ observed using Methylobacterium sp., Influence of Methylobacterium on seed imbibition to improving germination percentage of barnyard millet under dry land condition was reported by Poorniammal et al., (2020). When comparing other treatments, germinated rate declined as the concentration of PEG increased irrespective of the treatments. Among the two Methylobacterium species the $M$. aminovorans treated seeds added with PEG showed faster germination of seedlings at -1.5 bar (40\%) given in table 1 .

\section{Root, shoot and seedling length}

Root, shoot and seedling length were assessed at the end of germination test. The result showed that un-inoculated control had the highest values of root, shoot and seedling length at 0 bar $(1.7 \mathrm{~cm}, 1.1 \mathrm{~cm}$, and $2.2 \mathrm{~cm})$.

In the induced moisture stress by PEG the least values were observed at -0.5 bar $(1.3 \mathrm{~cm}$, $0.6 \mathrm{~cm}, 1.9 \mathrm{~cm})$ followed by -1 bar $(1.4 \mathrm{~cm}$, $0.6 \mathrm{~cm}, 2.0 \mathrm{~cm}),-1.5$ bar $(0.7 \mathrm{~cm}, 1.0 \mathrm{~cm}$, $1.8 \mathrm{~cm})$. The treated seeds of $M$. aminovorans showed maximum values of root, shoot and seedling length were observed at -3 bar $(2.9 \mathrm{~cm}, 1.9 \mathrm{~cm}, 4.8 \mathrm{~cm})$ followed by -1 bar $(2.7 \mathrm{~cm}, 1.4 \mathrm{~cm}, 4.1 \mathrm{~cm})$ while the least values were recorded at -0.5 bar $(1.2 \mathrm{~cm}, 0.6 \mathrm{~cm}$, $1.7 \mathrm{~cm}$ ) presented in table 1 . In the $M$. thiocyanatum showed maximum values of shoot length at -3 bars, root and seedling length at -2 bar $(2.7 \mathrm{~cm}, 4.1 \mathrm{~cm} 5.1 \mathrm{~cm})$.

As per the result of Ghosh et al., (2003) the Bacillus sp., inoculated in rice seeds showed higher root and shoot length than control thus, the bacteria increased the uptake of nutrients and water by plant, by increasing the root length. Methylobacterium spp. significantly increased the seedling height of red pepper and tomato (Madhaiyan et al., 2006; Ryu et al., 2006).

Priya et al., (2019) reported that the effect of single strain of $M$. radiotolerans in groundnut significantly increase the root and shoot length when compared to un-inoculated control. Inoculation of methylotrophic bacteria significantly enhanced the plant parameters of root and shoot length on groundnut (Krishnamoorthy et al., 2019). Among the two Methylobacterium species the $M$. thiocyanatum treated seeds added with PEG showed maximum shoot length at -3 bar, root and seedling length at -2 bar $(2.7 \mathrm{~cm}, 4.1 \mathrm{~cm}$ $5.1 \mathrm{~cm}$ ) of seedlings presented in Table 1. 


\section{Vigor index}

The vigor index of un-inoculated control showed highest value at 0 bar (48.3). The induced moisture stress by PEG the least values were recorded at1.5 bar (7.2), followed by -0.5 bar (14.9), 1 bar (21.2). In the $M$. aminovorans showed maximum vigor index at -1 bar (131.2) followed by -1.5 bar (116.5) while the least values were recorded at -0.5 bar (43.2). The treated seeds of $M$. thiocyanatum showed maximum vigor index at 0 bar (170.8) with other treatments showed decline in vigor index given in table 1. Similar results are in support of the findings of Kumar et al., (2016) reported that the inoculation of Bacillus amyloliqufaciens and Pseudomonas putida enhanced the vigor index in chickpea under stressed condition and increasing potential to mitigate the stress. Senthil kumar and Krishnamoorthy et al., (2017) reported the influence of Methylobacterium inoculation on increasing the seed germination and vigor index of tomato over un-inoculated control. In addition to this Poorniammal et al., (2020) conducted a field experiment under dry land condition to study the effect of Methylobacterium on seed imbibition to improving vigor index of barnyard millet. When comparing other treatments, vigor index declined as the concentration of PEG increased irrespective of the treatments. Among the two Methylobacterium species the M.aminovorans treated seeds added with PEG showed maximum vigor index of seedlings at -1 bar (131.2) presented in table 1 .

\section{Root hair deformation}

The root hair deformation assay were carry out in tomato seedlings give away existence of deformed root hair structures in Methylobacterial treatments. A tiny lateral roots containing the site of deformation in root hairs was observed, (Clavijo et al., 2015) in which the deformation of root hair was triggered in a limited area of root zone, whereas it leads to arrest the enlargement of root hairs. Treated with Methylobacterium culture resulted in deformed root hairs with bulging at the root tip that were also observed in the tomato seedlings of present study. The assessment of root segment under bright field microscope exhibit hemispherical bulbous structures and resembles thick short root hair that could not be observed in un-inoculated tomato seedlings and the similar result was showed in the rice crop (Senthil kumar et al., 2009) (Fig 1.). For inoculated seedlings, the most striking results of bacterial inoculation on root growth were a significant increase in the production of root hairs. For plants inoculated with the rhizospheric strains Ensifer sp., Chryseobacterium and all endophytes inoculated seedlings increases of root hair formation were observed (Abba Mondi et al., 2016). In the Methylobacterium treated seedlings observed the number of root hairs increased in a $1 \mathrm{~cm}$ section from the starting point of the root to the differentiation zone as compared with control seedlings. The treated $M$. aminovorans exhibit maximum number of root hairs (450) followed by $M$. thiocyanatum (441) as compared to uninoculated control (430) presented in table 2. Similar results were found in the maximum number of root hairs were formed in treated Methylobacterium strains as compared to control (Krishnamoorthy et al., 2018). Infected root hairs of $M$. aminovorans and $M$. thiocyanatum appeared like root tip bulging and thick short root hair followed by uninoculated control resembles like long and slender root hairs. The maximum number of infected root hairs in M. aminovorans (255) followed by M. thiocyanatum (223) and an uninoculated control showed no root hair infection. In un-inoculated control showed greater root hair length $(104.4 \mu \mathrm{m})$ as compared to treated $M$. aminovorans $(80.2 \mu \mathrm{m})$ and $M$. thiocyanatum $(72.4 \mu \mathrm{m})$. 
Table.1 Growth parameters of tomato seedlings variety PKM-1 influenced by the seed imbibition on M. aminovorans (MtTm13), M.thiocyanatum (DSM 11490 ${ }^{\mathrm{T}}$ ) under different PEG 6000 concentrations (0 to -3bars)

\begin{tabular}{|c|c|c|c|c|c|c|c|c|}
\hline Treatments & & $\begin{array}{l}\text { Peg } \\
\text { ncentration } \\
\text { (bars) }\end{array}$ & $\begin{array}{c}\text { Speed of } \\
\text { germination }\end{array}$ & $\begin{array}{c}\text { Germination } \\
(\%)\end{array}$ & $\begin{array}{l}\text { Root length } \\
\text { (cm) }\end{array}$ & $\begin{array}{c}\text { Shoot } \\
\text { length }(\mathrm{cm})\end{array}$ & $\begin{array}{l}\text { Seedling } \\
\text { length }(\mathbf{c m})\end{array}$ & $\begin{array}{l}\text { Vigor } \\
\text { index }\end{array}$ \\
\hline \multirow{4}{*}{$\begin{array}{c}T_{1}(\text { Un-inoculated } \\
\text { control })\end{array}$} & & 0 & $1.91 \pm 0.009^{\mathrm{h}}$ & $17.2 \pm 0.14^{\mathrm{k}}$ & $1.7 \pm 0.009^{\mathrm{h}}$ & $1.1 \pm 0.01^{\mathrm{f}}$ & $2.2 \pm 0.24^{\mathrm{h}}$ & $48.3 \pm 0.03^{k}$ \\
\hline & & -0.5 & $0.86 \pm 0.007^{1}$ & $7.9 \pm 0.02^{\mathrm{m}}$ & $1.3 \pm 0.014^{\mathrm{i}}$ & $0.6 \pm 0.007^{i}$ & $1.9 \pm 0.02^{i}$ & $14.9 \pm 0.22^{\mathrm{n}}$ \\
\hline & & -1 & $1.21 \pm 0.02^{j}$ & $10.5 \pm 0.02^{1}$ & $1.4 \pm 0.02^{\mathrm{i}}$ & $0.6 \pm 0.01^{i}$ & $2.0 \pm 0.02^{\mathrm{h}}$ & $21.2 \pm 0.06^{\mathrm{m}}$ \\
\hline & & -1.5 & $0.6 \pm 0.002^{\mathrm{m}}$ & $4.0 \pm 0.02^{\mathrm{n}}$ & $0.7 \pm 0.02^{\mathrm{k}}$ & $1.0 \pm 0.002^{\mathrm{g}}$ & $1.8 \pm 0.02^{i}$ & $7.2 \pm 0.04^{\circ}$ \\
\hline \multirow{7}{*}{$\begin{array}{c}T_{2} \text { (M. aminovorans } \\
\text {-MtTm13) }\end{array}$} & & 0 & $2.3 \pm 0.01^{\mathrm{f}}$ & $24.0 \pm 0.02^{\mathrm{h}}$ & $2.7 \pm 0.007^{\mathrm{c}}$ & $1.1 \pm 0.01^{\mathrm{f}}$ & $3.8 \pm 0.02^{\mathrm{d}}$ & $91.2 \pm 0.50^{\mathrm{f}}$ \\
\hline & & -0.5 & $2.1 \pm 0.02^{\mathrm{g}}$ & $24.0 \pm 0.43^{\mathrm{h}}$ & $1.2 \pm 0.02^{j}$ & $0.6 \pm 0.007 \mathrm{i}$ & $1.7 \pm 0.02^{j}$ & $43.2 \pm 0.58^{1}$ \\
\hline & & -1 & $3.0 \pm 0.06^{\mathrm{c}}$ & $32.0 \pm 0.24^{\mathrm{d}}$ & $2.7 \pm 0.03^{\mathrm{c}}$ & $1.4 \pm 0.01^{\mathrm{c}}$ & $4.1 \pm 0.07^{c}$ & $131.2 \pm 2.1^{\mathrm{b}}$ \\
\hline & & -1.5 & $3.2 \pm 0.06^{b}$ & $40.0 \pm 0.73^{b}$ & $2.2 \pm 0.03^{f}$ & $1.3 \pm 0.009^{\mathrm{d}}$ & $3.4 \pm 0.05^{\mathrm{e}}$ & $116.5 \pm 1.2^{\mathrm{d}}$ \\
\hline & & -2 & $1.7 \pm 0.02^{1}$ & $21.3 \pm 0.02^{1}$ & $2.0 \pm 0.03^{\mathrm{g}}$ & $1.2 \pm 0.01^{\mathrm{e}}$ & $3.1 \pm 0.07^{\mathrm{t}}$ & $68.2 \pm 0.7^{1}$ \\
\hline & & -2.5 & $2.5 \pm 0.01^{\mathrm{e}}$ & $29.3 \pm 0.09^{\mathrm{e}}$ & $2.5 \pm 0.04^{\mathrm{d}}$ & $1.3 \pm 0.007^{\mathrm{d}}$ & $3.7 \pm 0.02^{\mathrm{d}}$ & $111.3 \pm 0^{\mathrm{e}}$ \\
\hline & & -3 & $1.6 \pm 0.02^{1}$ & $18.5 \pm 0.02^{\mathrm{J}}$ & $2.9 \pm 0.05^{b}$ & $1.9 \pm 0.02^{b}$ & $4.8 \pm 0.07^{b}$ & $89.3 \pm 0.01^{\mathrm{t}}$ \\
\hline \multirow{7}{*}{$\begin{array}{c}\mathrm{T}_{3}(\mathrm{M} . \\
\text { thiocyanatum - } \\
\text { DSM11490 }^{\mathrm{T}} \text { ) }\end{array}$} & & 0 & $4.1 \pm 0.01^{\mathrm{a}}$ & $42.7 \pm 0.09^{\mathrm{a}}$ & $2.7 \pm 0.03^{\mathrm{c}}$ & $1.3 \pm 0.02^{\mathrm{d}}$ & $4.0 \pm 0.02^{\mathrm{c}}$ & $170.8 \pm 1.6^{\mathrm{a}}$ \\
\hline & & -0.5 & $3.0 \pm 0.04^{\mathrm{c}}$ & $33.3 \pm 0.19^{c}$ & $2.4 \pm 0.04^{\mathrm{d}}$ & $1.0 \pm 0.007^{\mathrm{g}}$ & $3.3 \pm 0.02^{\mathrm{e}}$ & $113.2 \pm 1.3^{\mathrm{d}}$ \\
\hline & & -1 & $2.3 \pm 0.03^{f}$ & $26.7 \pm 0.19^{\mathrm{g}}$ & $2.3 \pm 0.02^{\mathrm{e}}$ & $0.9 \pm 0.01^{\mathrm{h}}$ & $3.1 \pm 0.07^{f}$ & $85.4 \pm 0^{\mathrm{g}}$ \\
\hline & & -1.5 & $2.8 \pm 0.03^{\mathrm{d}}$ & $28.0 \pm 0.53^{\mathrm{f}}$ & $1.6 \pm 0.02^{\mathrm{h}}$ & $1.3 \pm 0.01^{\mathrm{d}}$ & $2.9 \pm 0.02^{\mathrm{g}}$ & $81.2 \pm 0.92^{\mathrm{h}}$ \\
\hline & & -2 & $2.7 \pm 0.009^{\mathrm{d}}$ & $24.0 \pm 0.48^{\mathrm{h}}$ & $4.1 \pm 0.07^{\mathrm{a}}$ & $1.0 \pm 0.002^{\mathrm{g}}$ & $5.1 \pm 0.02^{\mathrm{a}}$ & $122.4 \pm 2.3^{\mathrm{c}}$ \\
\hline & & -2.5 & $2.1 \pm 0.02^{\mathrm{g}}$ & $21.2 \pm 0.09^{i}$ & $1.7 \pm 0.002^{\mathrm{h}}$ & $1.0 \pm 0.01^{\mathrm{g}}$ & $2.6 \pm 0.02^{\mathrm{g}}$ & $57.5 \pm 0.73^{j}$ \\
\hline & & -3 & $1.1 \pm 0.005^{\mathrm{k}}$ & $10.6 \pm 0.02^{1}$ & $1.2 \pm 0.01^{j}$ & $2.7 \pm 0.005^{\mathrm{a}}$ & $3.8 \pm 0.07^{\mathrm{d}}$ & $41.7 \pm 0.77^{1}$ \\
\hline \multirow{7}{*}{ Mean } & \multirow{3}{*}{$\mathrm{T}$} & $\mathrm{T}_{1}$ & $0.65^{\mathrm{c}}$ & $5.6^{\mathrm{c}}$ & $0.73^{\mathrm{b}}$ & $0.46^{\mathrm{c}}$ & $1.11^{\mathrm{b}}$ & $13.0^{c}$ \\
\hline & & $\mathrm{T}_{2}$ & $2.3^{\mathrm{b}}$ & $26.9^{\mathrm{a}}$ & $2.31^{\mathrm{a}}$ & $1.25^{\mathrm{b}}$ & $3.51^{\mathrm{a}}$ & $92.9^{b}$ \\
\hline & & $\mathrm{T}_{3}$ & $2.5^{\mathrm{a}}$ & $26.6^{\mathrm{b}}$ & $2.28^{\mathrm{a}}$ & $1.30^{\mathrm{a}}$ & $3.54^{\mathrm{a}}$ & $96.0^{\mathrm{a}}$ \\
\hline & \multirow{4}{*}{ S } & $\mathrm{S}_{1}$ & $2.7^{\mathrm{a}}$ & $27.9^{\mathrm{a}}$ & $2.3^{\mathrm{a}}$ & $1.1^{\mathrm{c}}$ & $3.3^{\mathrm{a}}$ & $103.4^{\mathrm{a}}$ \\
\hline & & $\mathrm{S}_{2}$ & $1.9^{\mathrm{c}}$ & $21.7^{\mathrm{d}}$ & $1.6^{\mathrm{d}}$ & $0.7^{\mathrm{f}}$ & $2.3^{\mathrm{e}}$ & $57.0^{\mathrm{e}}$ \\
\hline & & $\mathrm{S}_{3}$ & $2.1^{\mathrm{b}}$ & $23.0^{c}$ & $2.1^{\mathrm{b}}$ & $0.9^{\mathrm{d}}$ & $3.0^{\mathrm{b}}$ & $79.2^{b}$ \\
\hline & & $\mathrm{S}_{4}$ & $2.1^{\mathrm{b}}$ & $23.9^{\mathrm{b}}$ & $1.5^{\mathrm{e}}$ & $1.1^{\mathrm{b}}$ & $2.6^{\mathrm{d}}$ & $68.2^{c}$ \\
\hline
\end{tabular}




\begin{tabular}{|c|c|c|c|c|c|c|c|}
\hline & $\mathrm{S}_{5}$ & $1.4^{\mathrm{e}}$ & $15.0^{\mathrm{f}}$ & $2.0^{c}$ & $0.7^{\mathrm{f}}$ & $2.7^{\mathrm{c}}$ & $63.5^{\mathrm{d}}$ \\
\hline & $\mathrm{S}_{6}$ & $1.5^{\mathrm{d}}$ & $16.8^{\mathrm{e}}$ & $1.4^{\mathrm{f}}$ & $0.8^{\mathrm{e}}$ & $2.1^{\mathrm{f}}$ & $56.2^{\mathrm{e}}$ \\
\hline Grand Mean & & 1.85 & 19.75 & 1.77 & 1.00 & 2.72 & 67.3 \\
\hline \multirow[t]{2}{*}{ SE d } & $\mathrm{S}$ & 0.03 & 0.3 & 0.03 & 0.01 & 0.06 & 0.94 \\
\hline & $\mathrm{T} \times \mathrm{S}$ & 0.05 & 0.5 & 0.06 & 0.02 & 0.11 & 1.64 \\
\hline \multirow{2}{*}{$\mathrm{CD}(\mathrm{P}=\mathbf{0 . 0 5})$} & $\mathrm{T}$ & 0.04 & 0.4 & 0.04 & 0.02 & 0.08 & 1.25 \\
\hline & $\mathrm{T} \times \mathrm{S}$ & 0.19 & 1.0 & 0.11 & 0.05 & 0.23 & 3.31 \\
\hline
\end{tabular}

Seeds were placed in sterile petridish, after 12 hours adding different PEG 6000 concentration ( 0 to -3 bars) and observe the growth parameters on $15^{\text {th }}$ day. There is no growth observed on un-inoculated control (-2 to -3 bars). Each value represents mean \pm SE of 3 replicates per treatment. In the similar column, significant differences at $(\mathrm{P}<0.05)$ levels are indicated by different letters. Data followed by similar letter in the similar column are not significantly different from each other. $\mathbf{T}=$ Treatments, $\mathbf{S}=$ PEG concentrations, un- inoculated control (T1), Methylobacterium aminovorans $(\mathrm{MtTm} 13)(\mathbf{T} 2)$, Methylobacterium thiocyanatum (DSM11490T) (T3).

Table.2 Root hairs parameters of tomato seedlings variety PKM1 influenced by the seed imbibitions on M. aminovorans (MtTm13), M.thiocyanatum $\left(\mathrm{DSM} 11490^{\mathrm{T}}\right.$ ) under different PEG 6000 concentrations

\begin{tabular}{|c|c|c|c|}
\hline Particulars & $\left.\mathbf{( T}_{\mathbf{1}}\right)$ Control & $\left.\mathbf{( T}_{\mathbf{2}}\right)$ M. aminovorans & $\left.\mathbf{( T}_{\mathbf{3}}\right)$ M.thiocyanatum \\
\hline Number of root hairs & 430 & 450 & 441 \\
\hline Number of infected root hairs & - & 255 & 223 \\
\hline Number of uninfected root hairs & 430 & 195 & 218 \\
\hline Root hair length $(\boldsymbol{\mu m})$ & 104.4 & 80.2 & 72.4 \\
\hline Root hair breadth $(\boldsymbol{\mu m})$ & 2.4 & 2.9 & 3.2 \\
\hline
\end{tabular}

The surface sterilized tomato seeds were treated with Methylobacterium spp. and placed in moistened filter paper in sterile petridish and incubates at $25^{\circ} \mathrm{C}$. After 5-7days the lateral root of seedlings showed abundant root hair. All the root hairs were observed under microscope by mounting one root per presterilized slide where the entire root was observed to be not deformed. Thus, Methylobacterium spp. was inoculated to the seedlings after a period of day the roots stained by aniline blue/ lactophenol stain (White et al., 2014) the deformed root hairs were observed. Root hair deformations were observed using bright field microscope. $\mathrm{T}=$ Treatments, un- inoculated control (T1), Methylobacterium aminovorans (MtTm13) (T2), Methylobacterium thiocyanatum (DSM11490T) (T3). 
Table.3 Biochemical parameters of tomato seedlings variety PKM1 influenced by the seed imbibition on M. aminovorans MtTm13, M.thiocyanatum (DSM $11490^{\mathrm{T}}$ ) under different PEG 6000 concentrations

\begin{tabular}{|c|c|c|c|c|c|c|}
\hline Treatments & $\begin{array}{c}\text { PEG } \\
\text { concentration } \\
\text { (bar) }\end{array}$ & $\begin{array}{l}\text { Proline ( } \mu \text { mol } \\
\mathrm{g}^{-1} \text { fresh leaf } \\
\text { tissue })\end{array}$ & $\begin{array}{l}\text { Glycine } \\
\text { Betaine }\left(\mu g g^{-1}\right. \\
\text { fresh leaf } \\
\text { tissue) }\end{array}$ & $\begin{array}{c}\text { Catalase }(\mu \text { molmin } \\
\left.\mathrm{g}^{-1} \text { of leaf tissues }\right)\end{array}$ & $\begin{array}{l}\text { Peroxidase }\left(\mathrm{min}^{-1}\right. \\
\mathrm{g}^{-1} \text { of leaf tissues) }\end{array}$ & $\begin{array}{l}\operatorname{SOD}\left(\mu \mathrm{g}^{-1}\right. \\
\text { protein } \mathrm{min}^{-1} \\
\text { of leaf tissue })\end{array}$ \\
\hline $\begin{array}{c}\mathbf{T}_{1}(\mathrm{Un}- \\
\text { inoculated } \\
\text { control })\end{array}$ & - & $3.42 \pm 0.026^{c}$ & $0.19 \pm 0.007^{c}$ & $1.03 \pm 0.002^{\mathrm{a}}$ & $1.24 \pm 0.01^{\mathrm{a}}$ & $16.2 \pm 0.27^{\mathrm{a}}$ \\
\hline $\begin{array}{c}\mathrm{T}_{2}(M . \\
\text { aminovorans - } \\
\text { MtTm13) }\end{array}$ & -1.5 & $3.96 \pm 0.079^{a}$ & $0.62 \pm 0.002^{b}$ & $0.28 \pm 0.005^{c}$ & $0.11 \pm 0.00^{c}$ & $11.5 \pm 0.17^{\mathrm{c}}$ \\
\hline $\begin{array}{c}\mathrm{T}_{3}(M . \\
\text { thiocyanatum - } \\
\left.\text { DSM11490 }^{\mathrm{T}}\right)\end{array}$ & -2 & $3.77 \pm 0.008^{b}$ & $0.75 \pm 0.006^{\mathrm{a}}$ & $0.35 \pm 0.006^{\mathrm{b}}$ & $0.16 \pm 0.00^{b}$ & $12.8 \pm 0.18^{b}$ \\
\hline Grand mean & & 3.71 & 0.52 & 0.55 & 0.50 & 13.5 \\
\hline SEd & & 0.084 & 0.01 & 0.008 & 0.01 & 0.37 \\
\hline $\begin{array}{c}\text { CD } \\
(\mathbf{P}=0.05)\end{array}$ & & 0.20 & 0.04 & 0.020 & 0.02 & 0.91 \\
\hline
\end{tabular}

Seeds were placed in sterile petridish, after 12 hours adding PEG 6000 concentration of ( -1.5 bar in $\mathrm{T}_{2} \&-2$ bar in $\mathrm{T}_{3}$ ) and $\mathrm{T}_{1}$ as un-inoculated Control without adding PEG 6000 concentration and then observations were taken on $15^{\text {th }}$ day. Each value represents mean \pm SE of 5 replicates per treatment. In the similar column, significant differences at $(\mathrm{P}<0.05)$ levels are indicated by different letters. Data followed by similar letter in the similar column are not significantly different from each other. $\mathrm{T}=$ Treatments, $\mathrm{S}=\mathrm{PEG}$ concentrations, un- inoculated control (T1), Methylobacterium aminovorans MtTm13 (T2), Methylobacterium thiocyanatum (DSM11490T) (T3). 
Fig.1 Tomato root hair infection and deformation assay observed under Bright field microscope @ 40X magnification (a) Un-inoculated control roots shown long and slender root hairs under induced moisture stress tolerance. Tomato root hairs infected by (b) Methylobacterium aminovorans (c) Methylobacterium thiocyanatum under induced moisture stress toleranceshowing root tip bulging and thick short root hair

\section{(A)}
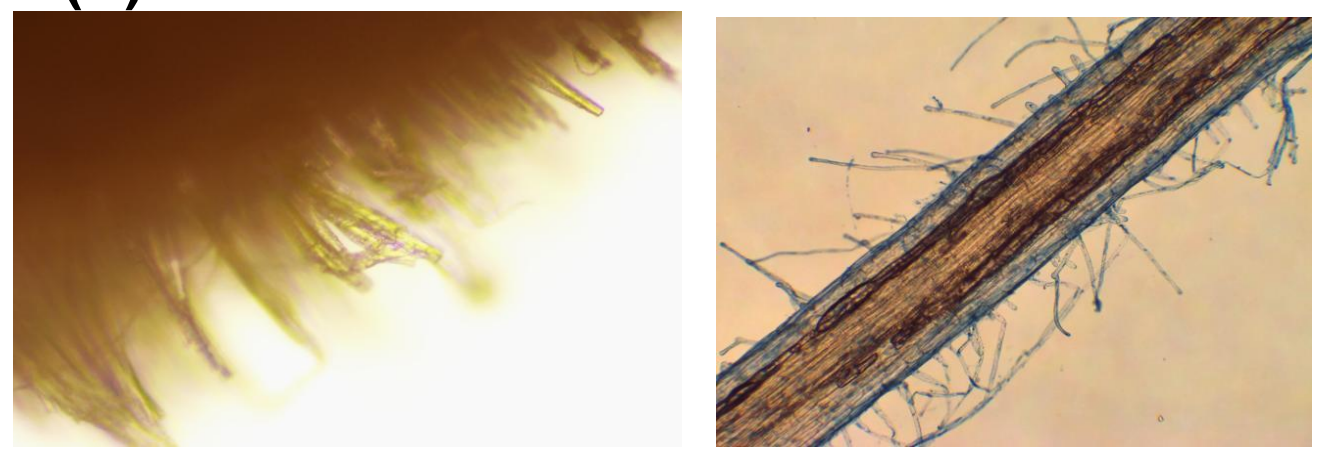

(B)
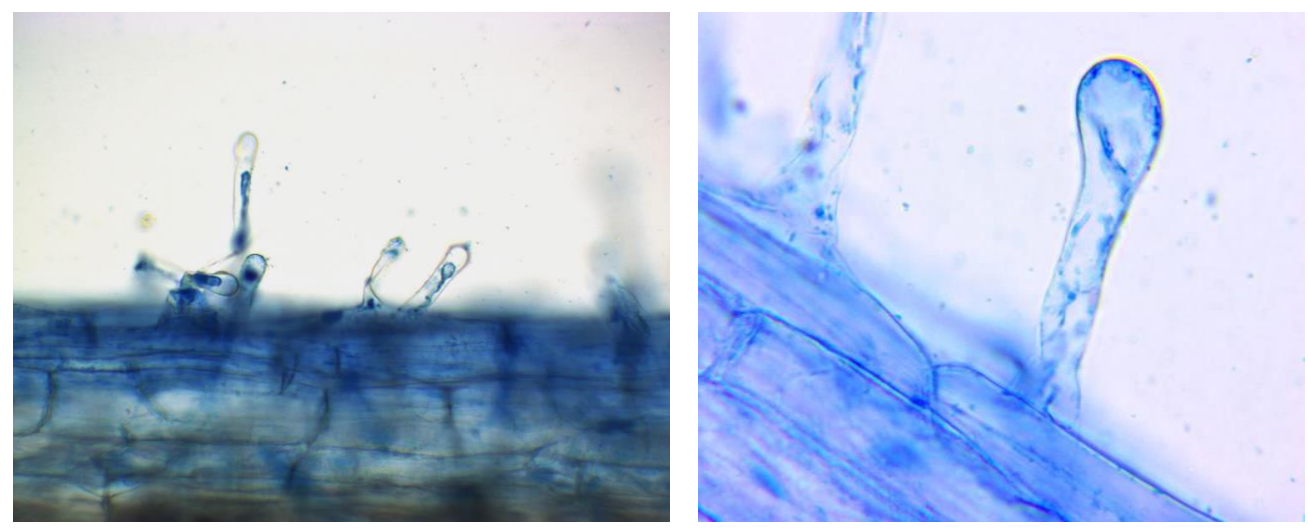

(C)
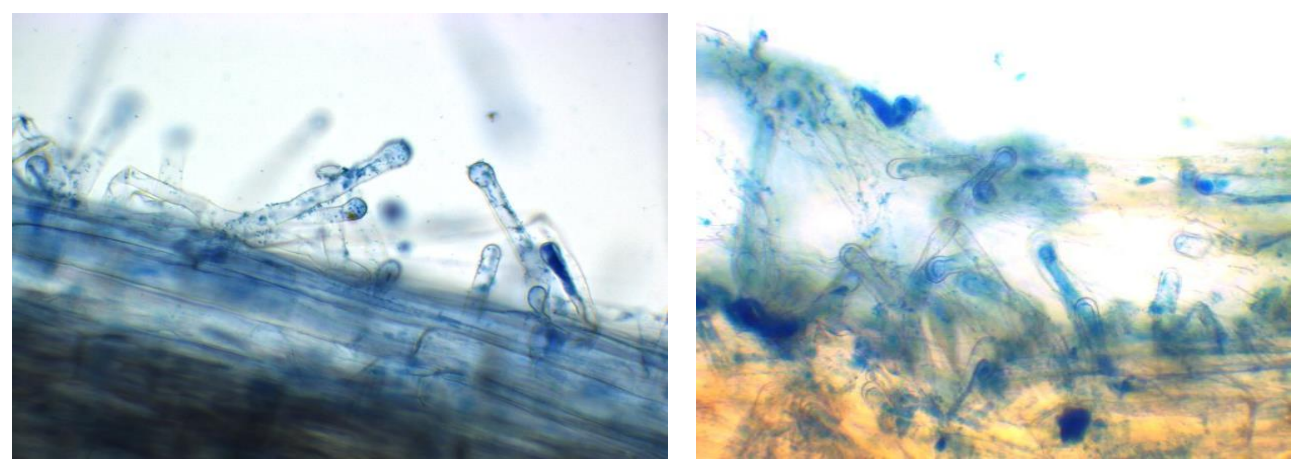
Inoculated M.thiocyanatum $(3.2 \mu \mathrm{m})$ exhibit higher root hair breadth followed by $M$. aminovorans $(2.9 \mu \mathrm{m})$ than un-inoculated control $(2.4 \mu \mathrm{m})$ presented in table 2 .

\section{Effect of PEG -6000 (0 to -3bars) induced osmotic stress on antioxidant enzymes}

The results pertaining to the effect of PEG6000 induced water stress on superoxide dismutase (SOD), catalase (CAT) and peroxidase (PER) are summarized in table 3 . Antioxidant enzymes play a major role in reducing the content of reactive oxygen species in plants which produced under stress condition. Earlier, several studies have shown the role of antioxidant enzymes for stimulating plant growth under salt stress condition (Subramanian et al., 2016). The activities of antioxidant enzymes examined in this study (SOD, POD, and CAT) increased significantly in the inoculated tomato seedlings under moisture stress compared to the un-inoculated control. The minimum growth of the seedlings was recorded up to PEG concentration (0 to 1.5 bars) and no growth was recorded in remaining concentration ( -2 to -3 bars) in uninoculated control which shows that the seedlings were exposed to severe drought osmotic stress by inducing PEG.

Then the Methylobacterium spp. inoculated treatments showed the growth of the seedlings in all PEG concentration (0 to -3 bars) whereas based on the maximum speed of germination and germination percentage the more vigorous growth was observed in -1.5 bars of $M$. aminovorans and -2 bars of $M$. thiocyanatum based on seedling length. It shows that the seedlings has the capability to withstand osmotic stress, these two different concentrations were further processed to analyze antioxidant enzyme activity. The catalase activity did not significantly differ among the treatments under a non-stressed condition which showed the decreased activity of catalase enzyme. The CAT activity increased under the drought condition was found in inoculated $M$. aminovorans $\left(0.28 \mu\right.$ molmin $^{-1} \mathrm{~g}^{-1}$ of leaf tissues $)$ followed by M. thiocyanatum $\left(0.35 \mu \mathrm{molmin}^{-1} \mathrm{~g}^{-1}\right.$ of leaf tissues) given in table 3 . The least catalase activity was found in control $\left(1.03 \mu \mathrm{molmin}^{-1}\right.$ $\mathrm{g}^{-1}$ of leaf tissues). The results are in accordance with finding of Kumar et al., (2017) reported that Bacillus altitudinis and Methylobacterium spp. treated rice plants showed more catalase activity than control under drought stress. Impact of PPFM enhanced the catalase activity on tomato under drought condition (Chandrasekaran et al., 2017). The catalase activity increased in crops resulted from the foliar application of PPFM (Sivakumar et al., 2017). The treated $M$. aminovorans $\left(0.11 \mathrm{~min}^{-1} \mathrm{~g}^{-1}\right.$ leaf tissue) and $M$. thiocyanatum (0.16 $\mathrm{min}^{-1} \mathrm{~g}^{-1}$ leaf tissue) peroxidase values were reduced as compared to un-inoculated control (1.24 $\mathrm{min}^{-1} \mathrm{~g}^{-1}$ leaf tissue) given in table 3.The results were in accordance with the finding of Madhaiyan et al., (2006) showed that the inoculation of Methylobacterium sp., significantly enhanced the peroxidase enzymes on groundnut. POD content in the rape leaves treated with PGPR strains were decreased as compared with control (Ren et al., 2019). Catalase and peroxidase plays a significant role in the cell controlling by activating and deactivating of reactive oxygen species and also it was possible to generate many apoplastic enzymes under normal \& stress conditions (Sairam et al., 2005). The unscavanged $\mathrm{H}_{2} \mathrm{O}_{2}$ diffused from sorghum chloroplast to cytosol, efficiently scavenged by POX and CAT (Zhang and Kirkham 1996). SODs are a group of metalloenzymes that are considered to be the first defense against ROS that dismute ROS into $\mathrm{H}_{2} \mathrm{O}_{2}$ formed during stress. The level of SOD activity decreased under PEG concentration of inoculated $M$. aminovorans $\left(11.5 \mu \mathrm{g}^{-1}\right.$ protein $\mathrm{min}^{-1}$ leaf tissue) and $M$. thiocyanatum $\left(12.8 \mu \mathrm{g}^{-1}\right.$ protein $\mathrm{min}^{-1}$ leaf 
tissue) as compared to un-inoculated control $\left(16.2 \mu \mathrm{g}^{-1}\right.$ leaf tissue protein $\mathrm{min}^{-1}$ ) given in table 3.The results were in accordance with the treated Methylobacterium strain in snap bean were enhancing the antioxidant enzyme activity of SOD with PPFM significantly reduced when compared with control (Abd ElGawad et al., 2015). The enhanced activity of antioxidant enzymes are CAT, PER, SOD on tomato seedlings due to beneficial impacts of Methylobacterial treatments towards improved plant performance under moisture stress condition.

\section{Effect of PEG -6000 (0 to -3bars) induced osmotic stress on osmolytes}

The plant accumulates many compatible osmolytes under stress conditions, such as proline, glycine betaine (GB), starch, alcohol and soluble protein (Delauney and Varma 1993). The degree of stress tolerance in a variety of crop plants and enzymes involved in stress tolerance has been positively associated with levels of organic solutes like proline and GB (Garg and Noor 2009). The proline content was significantly influenced by both drought stress and Methylobacterial treatments. A considerable increased in the amount of free proline was observed in all the treatments due to drought stress. However, it was interesting note that $M$. aminovorans treated seedlings produced the highest concentration of proline $\left(3.96 \mu \mathrm{mol} \mathrm{g} \mathrm{g}^{-1}\right.$ fresh leaf tissues) relative to $M$. thiocyanatum $\left(3.77 \mu \mathrm{mol} \mathrm{g}^{-1}\right.$ fresh leaf tissues) and control $\left(3.42 \mu \mathrm{mol} \mathrm{g}{ }^{-1}\right.$ fresh leaf tissues) presented in table 3. Our results were supported by Sivakumar et al., (2017) showed PPFM treated tomato plants exhibit higher proline content when compared to un-inoculated control under drought conditions. In addition to this Ruiz-Sanchez et al., (2011) reported the Arbuscular mycorhiza and Azospirillum inoculation improved the content of proline in rice under drought conditions as compared to control. The inoculated Bacillus sp., on plant showed higher proline content and it had a greater tolerance to water stress conditions (Gusain et al., 2015).The drought stress induced by PEG-6000 enhancing the endogenous proline concentrations in tomato (Shtereva et al., 2008). The increased proline content, especially in tolerant genotypes for osmotic stress imposition by PEG, may be attributed to the multifunctional role of proline as a signaling molecule for modulating mitochondrial functions, controlling cell proliferation and triggering different gene expression, which may be necessary for plants to recovery from stress (Szabados and Savoure 2009).The treated Methylobacterium seedlings exhibit maximum enzyme activity than uninoculated control. As a result the higher GB content were observed in M.thiocyanatum (0.75 $\mu \mathrm{g} \mathrm{g}^{-1}$ fresh leaf tissue) followed by M.aminovorans $\left(0.62 \mu \mathrm{g} \mathrm{g}^{-1}\right.$ fresh leaf tissue) while compared to un-inoculated control $\left(0.19 \mu \mathrm{g} \mathrm{g}^{-1}\right.$ fresh leaf tissue) presented in table 3. Similarly, inoculated PGPR strains in maize plant accumulated significantly higher GB content than un-inoculated control under drought stress conditions (Sandhya et al., 2010). Therefore thus, the Methylobacterium spp. might be used in reducing the negative impact of drought stress and enhancing the growth production of tomato seedlings.

The present study showed that Methylobacterium spp. was capable of mitigating the moisture stress induced by PEG and also enhancing the seed germination, vigor index and antioxidant enzymes. It seems that Methylobacterium spp. influenced the biochemical parameters of tomato seedlings and helped them improving drought tolerance. Methylobacterium spp. proved to have a promising role in improving plant performance under drought condition. In conclusion, in recent year, the agricultural production was drastically reduced due to drought stress. For this dispute, use of $M$. 
aminovorans (MtTm13) and $M$. cyanatum (DSM11490T) mitigate the early growth stages of drought in tomato seedlings and its enhance the plant growth promoting parameters by inducing antioxidant enzymes under induced moisture stress condition.

\section{References}

Abbamondi, Gennaro Roberto, Giuseppina Tommonaro, Nele Weyens, Sofie Thijs, Wouter Sillen, Panagiotis Gkorezis, Carmine Iodice, Wesley de Melo Rangel, Barbara Nicolaus, and Jaco Vangronsveld. "Plant growth-promoting effects of rhizospheric and endophytic bacteria associated with different tomato cultivars and new tomato hybrids." Chemical and Biological Technologies in Agriculture 3, no. 1 (2016): 1-10.

Abd El-Gawad, H. G., M. F. M. Ibrahim, A. A. Abd El-Hafez, and A. Abou ElYazied. "Contribution of pink pigmented facultative Methylotrophic bacteria in promoting antioxidant enzymes, growth and yield of Snap Bean." synthesis 2 (2015): 4.

Abdul- Baki, Aref A., and James D. Anderson. "Vigor determination in soybean seed by multiple criteria 1." Crop science 13, no. 6 (1973): 630-633.

Ardanov, Pavlo, Angela Sessitsch, Hely Häggman, Natalia Kozyrovska, and Anna Maria Pirttilä. "Methylobacterium-induced endophyte community changes correspond with protection of plants against pathogen attack." PLoS One 7, no. 10 (2012): e46802.

Bates, L. S $\overline{\mathbb{H}}$, R. P茾 Waldren, and I. D. Teare. "Rapid determination of free proline for water-stress studies." Plant and soil 39, no. 1 (1973): 205-207.

Chandrasekaran, Akshaya, Maria del Pilar Sosa Idelchik, and J. Andrés Melendez.
"Redox control of senescence and agerelated disease." Redox biology 11 (2017): 91-102.

Chandrasekaran, Akshaya, Maria del Pilar Sosa Idelchik, and J. Andrés Melendez. "Redox control of senescence and agerelated disease." Redox biology 11 (2017): 91-102.

Chanratana, Mak, Manoharan Melvin Joe, Aritra Roy Choudhury, Rangasamy Anandham, Ramasamy Krishnamoorthy, Kiyoon Kim, Sunyoung Jeon, Joonho Choi, Jeongyun Choi, and Tongmin Sa. "Physiological response of tomato plant to chitosanimmobilized aggregated Methylobacterium oryzae CBMB20 inoculation under salinity stress." 3 Biotech 9, no. 11 (2019): 1-13.

Chaparro-Giraldo, A., R. M. Barata, S. M. Chabregas, R. A. Azevedo, and M. C. Silva-Filho. "Soybean leghemoglobin targeted to potato chloroplasts influences growth and development of transgenic plants." Plant cell reports 19, no. 10 (2000): 961-965.

Chauhan, Hemlata, D. J. Bagyaraj, G. Selvakumar, and S. P. Sundaram. "Novel plant growth promoting rhizobacteria-Prospects and potential." Applied Soil Ecology 95 (2015): 38-53.

Chinnadurai, C., D. Balachandar, and S. P. Sundaram. "Characterization of 1aminocyclopropane-1-carboxylate deaminase producing methylobacteria from phyllosphere of rice and their role in ethylene regulation." World Journal of Microbiology and Biotechnology 25, no. 8 (2009): 1403-1411.

Clavijo, Fernando, Issa Diedhiou, Virginie Vaissayre, Laurent Brottier, Jennifer Acolatse, Daniel Moukouanga, Amandine Crabos et al., "The Casuarina NIN gene is transcriptionally activated throughout Frankia root infection as well as in response to bacterial 
diffusible signals." New Phytologist 208, no. 3 (2015): 887-903.

Delauney, Ashton J., and Desh Pal S. Verma. "Proline biosynthesis and osmoregulation in plants." The plant journal 4, no. 2 (1993): 215-223.

Delmotte, Nathanaël, Claudia Knief, Samuel Chaffron, Gerd Innerebner, Bernd Roschitzki, Ralph Schlapbach, Christian von Mering, and Julia A. Vorholt. "Community proteogenomics reveals insights into the physiology of phyllosphere bacteria." Proceedings of the National Academy of Sciences 106, no. 38 (2009): 16428-16433.

Dhindsa, Rajinder S., P. A. M. E. L. A. Plumb-Dhindsa, and Trevor A. Thorpe. "Leaf senescence: correlated with increased levels of membrane permeability and lipid peroxidation, and decreased levels of superoxide dismutase and catalase." Journal of Experimental botany 32, no. 1 (1981): 93-101.

Dodd, Geraldine L., and Lisa A. Donovan. "Water potential and ionic effects on germination and seedling growth of two cold desert shrubs." American Journal of Botany 86, no. 8 (1999): 1146-1153.

Doni, Febri, I. Anizan, CMZ Che Radziah, Ahmad Hilmi Salman, Muhammad Hidayat Rodzihan, and Wan Mohtar Wan Yusoff. "Enhancement of Rice Seed Germination and Vigour by" Trichoderma" spp." Research Journal of Applied Sciences, Engineering and Technology 7, no. 21 (2014): 45474552.

Eevers, Nele, Jonathan D. Van Hamme, Eric M. Bottos, Nele Weyens, and Jaco Vangronsveld. "Draft genome sequence of Methylobacterium radiotolerans, a DDE-degrading and plant growthpromoting strain isolated from Cucurbita pepo." Genome announcements 3, no. 3 (2015).
Fatemeh, Ahmadloo, Tabari Masoud, Azadi Pejman, and Hamidi Aidin. "Effect of plant growth promoting rhizobacteria (PGPRs) and stratification on germination traits of Crataegus pseudoheterophylla Pojark. Seeds." Scientia Horticulturae 172 (2014): 6167.

Flickyngerova, S., K. Shtereva, V. Stenova, D. Hasko, I. Novotny, V. Tvarozek, P. Sutta, and E. Vavrinsky. "Structural and optical properties of sputtered $\mathrm{ZnO}$ thin films." Applied Surface Science 254, no. 12 (2008): 3643-3647.

Garg, Neera, and Zahid Noor. "Genotypic differences in plant growth, osmotic and antioxidative defence of Cajanus cajan (L.) Millsp. modulated by salt stress." Archives of Agronomy and Soil Science 55, no. 1 (2009): 3-33.

Ghosh, Sibdas, Jon N. Penterman, Rebecca D. Little, Rocky Chavez, and Bernard R. Glick. "Three newly isolated plant growth-promoting bacilli facilitate the seedling growth of canola, Brassica campestris." Plant Physiology and Biochemistry 41, no. 3 (2003): 277-281.

Govindaraj, Mahalingam, P. Shanmugasundaram, P. Sumathi, and A. R. Muthiah. "Simple, rapid and cost effective screening method for drought resistant breeding in pearl millet." Electronic journal of plant breeding 1, no. 4 (2010): 590-599.

Greive, C. M., and S. R. Grattan. "Rapid assay for determination of water-soluble quaternary amino compounds." Plant Soil 70, no. 2 (1983): 303-307.

Gusain, Yogendra Singh, U. S. Singh, and A. K. Sharma. "Bacterial mediated amelioration of drought stress in drought tolerant and susceptible cultivars of rice (Oryza sativa L.)." African Journal of Biotechnology 14, no. 9 (2015): 764-773.

Hammerschmidt, R., E. M. Nuckles, and J. 
Kuć. "Association of enhanced peroxidase activity with induced systemic resistance of cucumber to Colletotrichum lagenarium." Physiological Plant Pathology 20, no. 1 (1982): 73-82.

Hayat, Qaiser, Shamsul Hayat, Mohd Irfan, and Aqil Ahmad. "Effect of exogenous salicylic acid under changing environment: a review." Environmental and experimental botany 68, no. 1 (2010): 14-25.

Jorge, Gabriel Lemes, Anna Kisiala, Erin Morrison, Megan Aoki, Ana Paula Oliveira Nogueira, and RJ Neil Emery. "Endosymbiotic Methylobacterium oryzae mitigates the impact of limited water availability in lentil (Lens culinaris Medik.) by increasing plant cytokinin levels." Environmental and Experimental Botany 162 (2019): 525540.

Krishnamoorthy, R., Soon-Wo Kwon, K. Kumutha, M. Senthilkumar, S. Ahmed, Tongmin Sa, and R. Anandham. "Diversity of culturable methylotrophic bacteria in different genotypes of groundnut and their potential for plant growth promotion." 3 Biotech 8, no. 6 (2018): 1-11.

Kumar, Aswathy S., R. Sridar, and Sivakumar Uthandi. "Mitigation of drought in rice by a phyllosphere bacterium Bacillus altitudinis FD48." African Journal of Microbiology Research 11, no. 45 (2017): 1614-1625.

Kumar, Manoj, Sankalp Mishra, Vijaykant Dixit, Manoj Kumar, Lalit Agarwal, Puneet Singh Chauhan, and Chandra Shekhar Nautiyal. "Synergistic effect of Pseudomonas putida and Bacillus amyloliquefaciens ameliorates drought stress in chickpea (Cicer arietinum L.)." Plant signaling \& behavior 11 , no. 1 (2016): e1071004.

Kumar, Manoj, Sankalp Mishra, Vijaykant
Dixit, Manoj Kumar, Lalit Agarwal, Puneet Singh Chauhan, and Chandra Shekhar Nautiyal. "Synergistic effect of Pseudomonas putida and Bacillus amyloliquefaciens ameliorates drought stress in chickpea (Cicer arietinum L.)." Plant signaling \& behavior 11 , no. 1 (2016): e1071004.

Larher, F., L. Leport, M. Petrivalsky, and M. Chappart. "Effectors for the osmoinduced proline response in higher plants." Plant physiology and biochemistry (Paris) 31, no. 6 (1993): 911-922.

Luna, Estrella, Emily Beardon, Sabine Ravnskov, Julie Scholes, and Jurriaan Ton. "Optimizing chemically induced resistance in tomato against Botrytis cinerea." Plant disease 100, no. 4 (2016): 704-710.

Madhaiyan, M., S. Poonguzhali, H. S. Lee, K. Hari, S. P. Sundaram, and T. M. Sa. "Pink-pigmented facultative methylotrophic bacteria accelerate germination, growth and yield of sugarcane clone Co86032 (Saccharum officinarum L.)." Biology and fertility of soils 41, no. 5 (2005): 350-358.

Madhaiyan, Munusamy, Kam Lock Chan, and Lianghui Ji. "Draft genome sequence of Methylobacterium sp. strain L2-4, a leaf-associated endophytic $\mathrm{N}$-fixing bacterium isolated from Jatropha curcas L." Genome announcements 2, no. 6 (2014).

Madhaiyan, Munusamy, Selvaraj Poonguzhali, Jeounghyun Ryu, and Tongmin Sa. "Regulation of ethylene levels in canola (Brassica campestris) by 1aminocyclopropane-1-carboxylate deaminase-containing Methylobacterium fujisawaense." Planta 224, no. 2 (2006): 268-278.

Madhaiyan, Munusamy, Selvaraj Poonguzhali, Jeounghyun Ryu, and Tongmin Sa. "Regulation of ethylene levels in canola 
(Brassica campestris) by 1aminocyclopropane-1-carboxylate deaminase-containing Methylobacterium fujisawaense." Planta 224, no. 2 (2006): 268-278.

Madhaiyan, Munusamy, Selvaraj Poonguzhali, Jeounghyun Ryu, and Tongmin Sa. "Regulation of ethylene levels in canola (Brassica campestris) by 1aminocyclopropane-1-carboxylate deaminase-containing Methylobacterium fujisawaense." Planta 224, no. 2 (2006): 268-278.

Maguire, James D. "Speed of germinationAid in selection and evaluation for seedling emergence and vigor 1." Crop science 2, no. 2 (1962): 176-177.

Meena, Kamlesh K., Manish Kumar, Marina G. Kalyuzhnaya, Mahesh S. Yandigeri, Dhananjaya P. Singh, Anil K. Saxena, and Dilip K. Arora. "Epiphytic pinkpigmented methylotrophic bacteria enhance germination and seedling growth of wheat (Triticum aestivum) by producing phytohormone." Antonie Van Leeuwenhoek 101, no. 4 (2012): 777786.

Omer, Zahra S., Riccardo Tombolini, and Berndt Gerhardson. "Plant colonization by pink-pigmented facultative methylotrophic bacteria (PPFMs)." FEMS microbiology ecology 47, no. 3 (2004): 319-326.

Panse, V. C., and P. V. Sukhatme. "Statistical methods for Agricultural workers. III Rev." Ed. ICAR, New Delhi (1978).

Papen, Hans, Arthur Geßler, Elisabeth Zumbusch, and Heinz Rennenberg. "Chemolithoautotrophic nitrifiers in the phyllosphere of a spruce ecosystem receiving high atmospheric nitrogen input." Current microbiology 44, no. 1 (2002): 56-60.

Poorniammal, R., M. Senthilkumar, S. Prabhu, and K. Anandhi. "Effect of Methylobacterium on seed germination, growth and yield of Barnyard Millet (Echinochloa frumentacea Var. COKV 2) under Rainfed Condition." Journal of Pharmacognosy and Phytochemistry 9, no. 2 (2020): 1675-1677.

Priya, M., K. Kumutha, and M. Senthilkumar. "Impact of bacterization of Rhizobium and Methylobacterium radiotolerans on germination and survivability in groundnut seed." Int. J. Curr. Microbiol. App. Sci 8, no. 8 (2019): 394-405.

Raja, K., R. Anandham, and K. Sivasubramaniam. "Co-inoculation of liquid microbial cultures and compatibility with chemicals for improvement of seed germination and vigour in paddy." Int. J. Curr. Microbiol. App. Sci 7, no. 1 (2018): 2077-2085.

Ren, Xue-Min, Shi-Jun Guo, Wei Tian, Yan Chen, Hui Han, E. Chen, Bai-Lian Li, Yu-Ying Li, and Zhao-Jin Chen. "Effects of plant growth-promoting bacteria (PGPB) inoculation on the growth, antioxidant activity, $\mathrm{Cu}$ uptake, and bacterial community structure of rape (Brassica napus L.) grown in $\mathrm{Cu}-$ contaminated agricultural soil." Frontiers in microbiology 10 (2019): 1455.

Ruíz-Sánchez, Michel, Elisabet Armada, Yaumara Muñoz, Inés E. García de Salamone, Ricardo Aroca, Juan Manuel Ruíz-Lozano, and Rosario Azcón. "Azospirillum and arbuscular mycorrhizal colonization enhance rice growth and physiological traits under well-watered and drought conditions." Journal of plant physiology 168, no. 10 (2011): 1031-1037.

Ryu, Jeong-Hyun, Munusamy Madhaiyan, Selvaraj Poonguzhali, Woo-Jong Yim, Pandiyan Indiragandhi, Kyoung-A. Kim, Rangasamy Anandham, JongChul Yun, Kye-Hoon Kim, and 
Tongmin Sa. "Plant growth substances produced by Methylobacterium spp. and their effect on tomato (Lycopersicon esculentum L.) and red pepper (Capsicum annuum L.) growth." Journal of Microbiology and Biotechnology 16, no. 10 (2006): 16221628.

Ryu, Jeong-Hyun, Munusamy Madhaiyan, Selvaraj Poonguzhali, Woo-Jong Yim, Pandiyan Indiragandhi, Kyoung-A. Kim, Rangasamy Anandham, JongChul Yun, Kye-Hoon Kim, and Tongmin Sa. "Plant growth substances produced by Methylobacterium spp. and their effect on tomato (Lycopersicon esculentum L.) and red pepper (Capsicum annuum L.) growth." Journal of Microbiology and Biotechnology 16, no. 10 (2006): 16221628.

Saikia, Juthika, Rupak K. Sarma, Rajashree Dhandia, Archana Yadav, Rupjyoti Bharali, Vijai K. Gupta, and Ratul Saikia. "Alleviation of drought stress in pulse crops with ACC deaminase producing rhizobacteria isolated from acidic soil of Northeast India." Scientific reports 8, no. 1 (2018): 1-16.

Sairam, R. K., G. C. Srivastava, S. Agarwal, and R. C. Meena. "Differences in antioxidant activity in response to salinity stress in tolerant and susceptible wheat genotypes." Biologia Plantarum 49, no. 1 (2005): 85.

Sandhya, V. S. K. Z., Sk Z. Ali, Minakshi Grover, Gopal Reddy, and B. Venkateswarlu. "Effect of plant growth promoting Pseudomonas spp. on compatible solutes, antioxidant status and plant growth of maize under drought stress." Plant Growth Regulation 62, no. 1 (2010): 21-30.

Senthilkumar, M., and R. Krishnamoorthy. "Isolation and characterization of tomato leaf phyllosphere
Methylobacterium and their effect on plant growth." Int J Curr Microbiol App Sci 6, no. 11 (2017): 2121-2136.

Senthilkumar, M., M. Madhaiyan, S. P. Sundaram, and S. Kannaiyan. "Intercellular colonization and growth promoting effects of Methylobacterium sp. with plant-growth regulators on rice (Oryza sativa L. Cv CO-43)." Microbiological research 164, no. 1 (2009): 92-104.

Shukla, Nandani, R. P. Awasthi, Laxmi Rawat, and J. Kumar. "Biochemical and physiological responses of rice (Oryza sativa L.) as influenced by Trichoderma harzianum under drought stress." Plant Physiology and Biochemistry 54 (2012): 78-88.

Sidari, Maria, Carmelo Mallamaci, and Adele Muscolo. "Drought, salinity and heat differently affect seed germination of Pinus pinea." Journal of forest research 13, no. 5 (2008): 326-330.

Sivakumar, B. "Analysis of the Publications of the PSG College of Arts and Science: A Bibliometric Study." Journal of Advancements in Library Sciences (JoALS) 4, no. 1 (2017): 7-14p.

Sivakumar, B. "Analysis of the Publications of the PSG College of Arts and Science: A Bibliometric Study." Journal of Advancements in Library Sciences (JoALS) 4, no. 1 (2017): 7-14p.

Sivakumar, R., G. K. Nandhitha, P. Chandrasekaran, P. Boominathan, and M. Senthilkumar. "Impact of pink pigmented facultative methylotroph and PGRs on water status, photosynthesis, proline and NR activity in tomato under drought." Int J Curr Microbiol App Sci 6, no. 6 (2017): 1640-1651.

Sy, Abdoulaye, Eric Giraud, Philippe Jourand, Nelly Garcia, Anne Willems, Philippe De Lajudie, Yves Prin et al., "Methylotrophic Methylobacteriumbacteria nodulate and 
fix nitrogen in symbiosis with legumes." Journal of bacteriology 183, no. 1 (2001): 214-220.

Szabados, László, and Arnould Savouré. "Proline: a multifunctional amino acid." Trends in plant science 15 , no. 2 (2010): 89-97.

Tani, Akio, Nurettin Sahin, and Kazuhide Kimbara. "Methylobacterium oxalidis sp. nov., isolated from leaves of Oxalis corniculata." International journal of systematic and evolutionary microbiology 62, no. 7 (2012): 16471652.

Vardharajula, Sandhya, Shaik Zulfikar Ali, Minakshi Grover, Gopal Reddy, and Venkateswarlu Bandi. "Droughttolerant plant growth promoting Bacillus spp.: effect on growth, osmolytes, and antioxidant status of maize under drought stress." Journal of
Plant Interactions 6, no. 1 (2011): 1-14. White, R. W., R. Powell, and T. E. Johnson. "The effect of Mn on mineral stability in metapelites revisited: New $a-x$ relations for manganese- bearing minerals." Journal of Metamorphic Geology 32, no. 8 (2014): 809-828.

Yim, W. J., K. Y. Kim, Y. W. Lee, S. P. Sundaram, Y. Lee, and T. M. Sa. "Real time expression of ACC oxidase and PR-protein genes mediated by Methylobacterium spp. in tomato plants challenged with Xanthomonas campestris pv. vesicatoria." Journal of plant physiology 171, no. 12 (2014): 1064-1075.

Zhang, Jingxian, and M. B. Kirkham. "Antioxidant responses to drought in sunflower and sorghum seedlings." New phytologist 132, no. 3 (1996): 361-373.

\section{How to cite this article:}

Anitha, P., K. Kumutha, C. Raja Manickam, A. Kamaraj and Senthilkumar, M. 2021. Comparative Analysis of two Methylobacterium spp. for Mitigating Moisture Stress Induced by PEG in Early Growth Stages of Tomato. Int.J.Curr.Microbiol.App.Sci. 10(04): 66-83. doi: https://doi.org/10.20546/ijcmas.2021.1004.008 